\title{
Neuromodulators, Not Activity, Control Coordinated Expression of Ionic Currents
}

\author{
Olga Khorkova ${ }^{1}$ and Jorge Golowasch ${ }^{1,2}$ \\ ${ }^{1}$ Federated Department of Biological Sciences and 2 Department of Mathematical Sciences, New Jersey Institute of Technology, Newark, New Jersey 07102
}

\begin{abstract}
Electrical activity in identical neurons across individuals is often remarkably similar and stable over long periods. However, the ionic currents that determine the electrical activity of these neurons show wide animal-to-animal amplitude variability. This seemingly random variability of individual current amplitudes may obscure mechanisms that globally reduce variability and that contribute to the generation of similar neuronal output. One such mechanism could be the coordinated regulation of ionic current expression. Studying identified neurons of the Cancer borealis pyloric network, we discovered that the removal of neuromodulatory input to this network (decentralization) was accompanied by the loss of the coordinated regulation of ionic current levels. Additionally, decentralization induced large changes in the levels of several ionic currents. The loss of coregulation and the changes in current levels were prevented by continuous exogenous application of proctolin, an endogenous neuromodulatory peptide, to the pyloric network. This peptide does not exert fast regulatory actions on any of the currents affected by decentralization. We conclude that neuromodulatory inputs to the pyloric network have a novel role in the regulation of ionic current expression. They can control, over the long term, the coordinated expression of multiple voltage-gated ionic currents that they do not acutely modulate. Our results suggest that current coregulation places constraints on neuronal intrinsic plasticity and the ability of a network to respond to perturbations. The loss of conductance coregulation may be a mechanism to facilitate the recovery of function.
\end{abstract}

Key words: neuromodulation; ionic currents; coregulation; activity; crustacean; stomatogastric; decentralization

\section{Introduction}

Neuronal activity is mainly the result of the operation of ion channels, and their conductance levels are known to be highly variable (Liu et al., 1998; Golowasch et al., 1999a, 2002; Schulz et al., 2006). Despite this variability, neurons and neural networks can maintain remarkable functional stability under variable conditions (Davis, 2006), can restore their functional levels of activity after perturbations and injury (Thoby-Brisson and Simmers, 1998; Luther et al., 2003; Saghatelyan et al., 2005), and sometimes show great similarity of activity patterns across individuals (Bucher et al., 2005). It is therefore important to understand how this conductance variability can result in stable activity. One possibility is that the conductance levels are regulated by activitydependent feedback mechanisms that adjust activity levels to around certain set points. This has been shown at the synaptic (Turrigiano, 1999; Turrigiano and Nelson, 2004), neuronal (Turrigiano et al., 1994; Hong and Lnenicka, 1995; Galante et al., 2001; Xu et al., 2005; Davis, 2006), and network (Thoby-Brisson and Simmers, 1998; Golowasch et al., 1999b; Gonzalez-Islas and Wenner, 2006) levels.

Received March 21, 2007; revised June 26, 2007; accepted June 27, 2007.

This work was supported by National Institute of Mental Health Grant 64711. We thank Dr. Farzan Nadim for numerous comments and suggestions. We also thank Drs. Bruce Johnson and David Schulz for suggestions, Dr. Kaushik Ghosh for advice on statistical analysis, and Drs. Eve Marder and Pierre Meyrand for critically reading this manuscript.

Correspondence should be addressed to Jorge Golowasch, Department of Mathematical Sciences, New Jersey Institute of Technology, University Heights, Newark, NJ 07102. E-mail: jorge.p.golowasch@njit.edu.

DOI:10.1523/JNEUROSCI.1274-07.2007

Copyright $\odot 2007$ Society for Neuroscience $\quad$ 0270-6474/07/278709-10\$15.00/0
Other possibilities include activity-independent mechanisms, such as developmentally regulated ion channel expression programs (Linsdell and Moody, 1994; Spitzer, 2006). Furthermore, it is often found that conductance levels of two or more ionic currents are simultaneously regulated as a consequence of neuronal activity changes (Linsdell and Moody, 1994; Liu et al., 1998; Desai et al., 1999; Golowasch et al., 1999a; Gibson et al., 2006). Whether such simultaneous changes actually involve a coordinated regulation between multiple ionic currents is known for only a very small number of cases (McAnelly and Zakon, 2000; MacLean et al., 2003), and the coordinating mechanisms are unknown. In lobster stomatogastric ganglion (STG) neurons, an activityindependent mechanism seems to coordinate the conductance level of the outward A-current $\left(I_{\mathrm{A}}\right)$ with the conductance level of the hyperpolarization-activated inward current $\left(I_{\mathrm{h}}\right)$, resulting in the preservation of neuronal and network patterns of activity (MacLean et al., 2003; Burdakov, 2005). The coordination between these currents occurs at the transcript level (Schulz et al., 2006).

Here we report that the current density levels of three voltagegated ionic currents covary in pyloric dilator (PD) neurons of the crab STG and that this coordinated current regulation (henceforth referred to as coregulation) is controlled by central neuromodulatory input to the STG via slow-acting mechanisms that do not acutely modulate any of these currents.

\section{Materials and Methods}

The stomatogastric nervous system of cold-anesthetized Jonah crabs Cancer borealis was dissected as described previously (Selverston et al., 
1976; Harris-Warrick, 1992). The animals were obtained from local fishermen and kept in seawater aquaria at $\sim 14^{\circ} \mathrm{C}$. The stomatogastric nervous system was pinned onto Sylgard-lined Petri dishes (Sylgard 184; Dow Corning, Midland, MI) and superfused with chilled $\left(10-15^{\circ} \mathrm{C}\right)$ normal Cancer saline with the following composition (in mM): $440 \mathrm{NaCl}$, $11 \mathrm{KCl}, 13 \mathrm{CaCl}_{2}, 26 \mathrm{MgCl}_{2}, 5$ maleic acid, and 11 trizma base, $\mathrm{pH}$ 7.4-7.5. Organotypic cultures of the isolated stomatogastric nervous system were kept for up to $5 \mathrm{~d}$ in an incubator at $4-6^{\circ} \mathrm{C}$ in normal saline supplemented with $1 \mathrm{~g} /$ liter dextrose, $35 \mathrm{U} / \mathrm{ml}$ penicillin, and $50 \mathrm{U} / \mathrm{ml}$ streptomycin. $\mathrm{Mn}^{2+}\left(\right.$ or $\left.\mathrm{Ba}^{2+}\right)$ saline was made by substituting $12.9 \mathrm{~mm}$ $\mathrm{Mn}^{2+}\left(\right.$ or $\left.\mathrm{Ba}^{2+}\right)$ for $\mathrm{Ca}^{2+}$, always leaving $0.1 \mathrm{mM} \mathrm{Ca}^{2+}$ in the bath to ensure membrane stability (Golowasch and Marder, 1992a). Low concentrations of divalent cations ( $\leq 200 \mu \mathrm{M}$ ) were added without compensation. Unless otherwise specified, all chemicals were obtained from Fisher Scientific (Fairlawn, NJ). Tetrodotoxin (TTX) was obtained from Calbiochem (San Diego, CA), and proctolin was from Bachem (San Carlos, CA). Proctolin was bath applied as a $1 \mu \mathrm{M}$ solution in Cancer saline.

All data reported here are from PD neurons, which are located in the STG. Two PD neurons and the pacemaker anterior burster (AB) neuron of the network are members of the pyloric network and are electrically coupled. We made no attempt to isolate each neuron because, although current flow through gap junctions can contribute to ionic currents measured in any of these neurons, the contribution is negligible at the high voltages we used for our measurements (Rabbah et al., 2005). PD neurons were identified by matching intracellular action potential recordings to their corresponding extracellular recordings on either the lateral ventricular (lvn) or pyloric dilator motor nerves (Selverston et al., 1976; Harris-Warrick, 1992).

Most neuromodulatory inputs to the STG originate in adjacent ganglia connected to it via a single nerve, the stomatogastric nerve (stn). To remove the neuromodulatory inputs to the STG (decentralization), either the stn was transected or action potential transmission along the nerve was blocked by adding isotonic $(750 \mathrm{~mm})$ sucrose plus $0.1 \mu \mathrm{M}$ TTX to a Vaseline well built around the stn (Luther et al., 2003). The method of decentralization did not affect the results.

Electrophysiology. Extracellular recordings were made using stainless steel electrodes placed inside Vaseline wells built around motor nerves. Intracellular recordings from $\mathrm{PD}$ neurons were performed using glass electrodes filled with $0.6 \mathrm{M} \mathrm{K}_{2} \mathrm{SO}_{4}$ plus $20 \mathrm{mM} \mathrm{KCl}(15-30 \mathrm{M} \Omega$ resistance) inserted into the soma. An Axoclamp 2B (Molecular Devices, Union City, CA) was used for all intracellular recordings, and all data were acquired with a Digidata 1200A interface and pClamp 9.2 software (Molecular Devices).

Unless otherwise stated, all currents were measured in normal saline or normal saline supplemented with $0.1 \mu \mathrm{M}$ TTX. The presence of TTX during voltage-clamp measurements did not affect current amplitudes. TTX washed off completely in $\sim 2 \mathrm{~h}$. We detected no noticeable effect of short-term $(<30 \mathrm{~min})$ TTX applications on the process of activity recovery or current density changes after decentralization. All currents were measured in two-electrode voltage clamp as described previously (Golowasch and Marder, 1992a).

Leak currents generated at the test potentials $V_{\text {test }}$ were subtracted using the P/ $n$ method: $n$ subpulses of amplitude, $V_{\text {test }} / n$ were applied $(n=4-5)$ in the opposite direction from the test pulse, and the sum of the currents measured during the subpulses was added to the current measured at $V_{\text {test }}$.

Outward currents. We define a high-threshold potassium current $\left(I_{\mathrm{HTK}}\right)$ as the current activated in normal saline by applying $800 \mathrm{~ms}$ depolarizing voltage steps from a holding potential of $-40 \mathrm{mV}$, leak subtracted using the $\mathrm{P} / n$ method described above. A large fraction of this current is generated by the Ca-dependent $\mathrm{K}^{+}$current $\left(I_{\mathrm{KCa}}\right)$ (Golowasch and Marder, 1992a; Haedo and Golowasch, 2006). Peak $I_{\mathrm{HTK}}$ amplitudes were measured at $30 \mathrm{~ms}$ after the test pulse onset. Because $I_{\mathrm{A}}$ is fully inactivated at $-40 \mathrm{mV}, I_{\mathrm{HTK}}$ estimated using this protocol is not contaminated by $I_{\mathrm{A}}$. We determined the delayed rectifier current $\left(I_{\mathrm{Kd}}\right)$ as the current measured in the same way as $I_{\mathrm{HTK}}$ but in $\mathrm{Mn}^{2+}$-containing saline. $I_{\mathrm{KCa}}$ was estimated by subtracting total outward current measured in $\mathrm{Mn}^{2+}$ saline in response to $800 \mathrm{~ms}$ depolarizing voltage steps from a holding potential of $-40 \mathrm{mV}$ from the current measured in the same way in normal saline. Steady state $I_{\mathrm{HTK}}, I_{\mathrm{KCa}}$, or $I_{\mathrm{Kd}}$ values were measured at the end of the $800 \mathrm{~ms}$ pulse at $+40 \mathrm{mV}$. $I_{\mathrm{A}}$ was determined in normal saline taking advantage of its strong voltage dependence of inactivation, which distinguishes it from $I_{\mathrm{HTK}} . I_{\mathrm{A}}$ is known to be completely inactivated in pyloric neurons of $C$. borealis at $-40 \mathrm{mV}$ but nearly completely deinactivated at $-80 \mathrm{mV}$ (cf. Golowasch and Marder, 1992a). Thus, to estimate $I_{\mathrm{A}}$, we subtracted total outward current measured by applying $800 \mathrm{~ms}$ depolarizing voltage steps from a holding potential of $-40 \mathrm{mV}$ from the current measured at the same membrane potentials but from a holding voltage of $-80 \mathrm{mV} . I_{\mathrm{A}}$ amplitude was measured at $30 \mathrm{~ms}$ after the start of the pulse to $+40 \mathrm{mV}$. To confirm that $I_{\mathrm{A}}$ was not contaminated by $I_{\mathrm{HTK}}$, we evaluated the effects of partially blocking $I_{\mathrm{HTK}}$ with $\mathrm{Mn}^{2+}$ saline or with $10 \mathrm{~mm}$ tetraethylammonium (TEA) (Golowasch and Marder, 1992a) on our measurements of $I_{\mathrm{A}}$. We found no significant differences from the current measured in the same cells in normal saline $\left(I_{\mathrm{A}}\right.$ in normal saline, $96.1 \pm 51.5 \mathrm{nA} / \mathrm{nF}$; in TEA, $87.2 \pm 32.0 \mathrm{nA} / \mathrm{nF}, n=15$, $p=0.4 ; I_{\mathrm{A}}$ in normal saline, $109.9 \pm 29.6 \mathrm{nA} / \mathrm{nF} ;$ in $\mathrm{Mn}^{2+}, 105.8 \pm 40.0$ $\mathrm{nA} / \mathrm{nF}, n=18, p=0.5)$.

Inward currents. $I_{\mathrm{h}}$ was activated with hyperpolarizing pulses from a holding potential of $-40 \mathrm{mV}$. Maximum amplitude was measured at the end of an $8 \mathrm{~s}$ pulse at $-110 \mathrm{mV}$ after leak subtraction. To determine the leak current during $I_{\mathrm{h}}$ measurements, a linear fit to the $I-V$ curve at -60 to $-40 \mathrm{mV}$ was extrapolated to $-110 \mathrm{mV}$. $I_{\mathrm{Ba}}$ corresponds to the current flowing through $\mathrm{Ca}^{2+}$ channels but carried by Ba ions and was calculated as a difference between a current measured as described for $I_{\mathrm{HTK}}$ but in low $\mathrm{Ca}^{2+}$ saline plus $0.1 \mu \mathrm{M}$ TTX plus $10 \mathrm{~mm}$ TEA plus $12.9 \mathrm{mM} \mathrm{Ba}^{2+}$, and the same current measured in TTX plus TEA plus $\mathrm{Ba}^{2+}$ plus $200 \mu \mathrm{M}$ $\mathrm{Cd}^{2+}$ at $210 \mathrm{~ms}$ from the onset of the test pulse.

The membrane capacitance was determined by integrating the area of the capacitive current for voltage steps from -50 to $-60 \mathrm{mV}$. Current density was estimated by dividing the current amplitude by the membrane capacitance.

Examples of raw current traces and $I-V$ curves for all these currents are shown in Figure 2 (left and middle panels, respectively). Day 0 measurements correspond to initial control measurements taken in every condition tested. In decentralized preparations, day 0 measurements were taken immediately before decentralization. Measurement of all five different voltage-gated currents was not always possible in the same cell. Therefore, the sample sizes of the correlation graphs may differ.

Statistical analysis. All data are shown as averages \pm SD. Statistical significance was determined using linear regression analysis, $t$ tests, or one-way ANOVAs with Tukey's post hoc tests (SigmaStat 2.03; Aspire Software International, Leesburg, VA). Two-way mixed design ANOVAs, ANCOVAs, and multivariate analyses were performed using custom functions [SigmaStat 2.03 and Excel (Microsoft, Seattle, WA)].

\section{Results}

\section{Decentralization modifies pyloric network activity}

The pyloric network of the crustacean STG, when dissected together with the commissural and esophageal ganglia, retains most of the neuromodulatory inputs necessary for the expression of its rhythmic activity. These inputs can be experimentally interrupted in vitro by blocking action potential transmission along the single neuromodulatory input nerve (stn) to the STG (henceforth referred to as decentralization) (Luther et al., 2003). Pyloric activity is temporarily interrupted immediately after decentralization but can recover to near control levels hours to days later (Thoby-Brisson and Simmers, 1998; Golowasch et al., 1999b; Luther et al., 2003). An example of these changes in activity is shown in Figure 1. On the left (Control) are extracellular recordings of the main pyloric motor nerve and intracellular recordings of a PD neuron of a preparation in which the neuromodulatory input nerve is intact, shown at different times in organ culture (days 0,1 , and 4). Only a slight variation in the frequency of the rhythm is observed. If the neuromodulator-containing input nerve (stn) is severed, the pyloric rhythm ceases in seconds to minutes (Decentralized, Day 0 ). This activity recovers after $\geq 1 \mathrm{~d}$ 


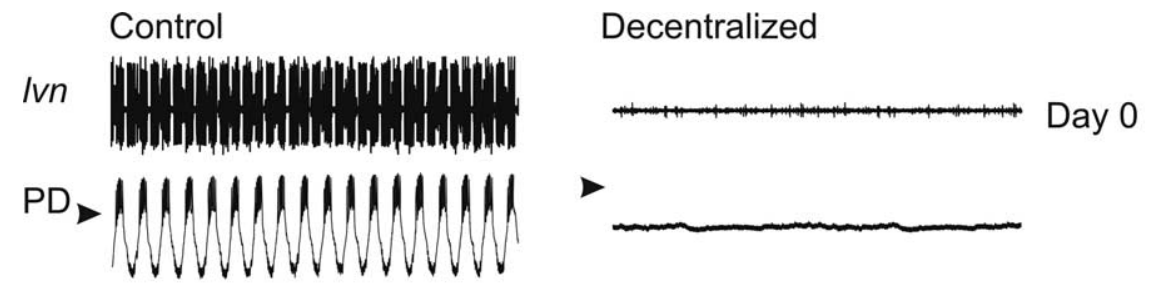

IVn
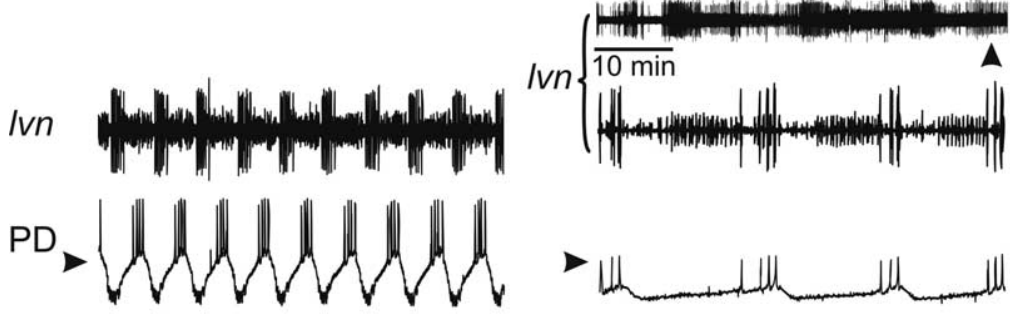

IVn
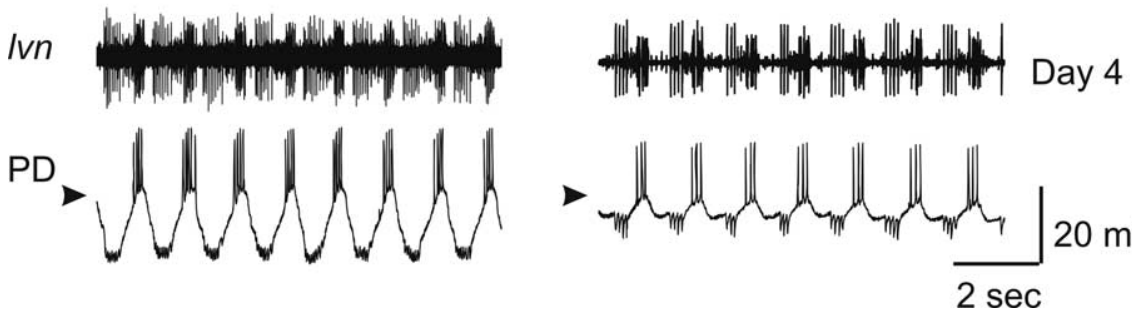

Figure 1. Effects of decentralization on pyloric network activity. All extracellular recordings were obtained from the lvn, and all intracellular recordings are from the PD neuron, in normal saline. Control (left column) and decentralized (right column) preparations were recorded at days 0,1 , and 4 in organ culture. Decentralized day 0 corresponds to activity $\sim 15$ min after decentralization. On day 1, the decentralized preparations showed bouts of pyloric activity lasting seconds to a few minutes and repeating at irregular intervals of minutes to hours (top Ivn panel) comprising the so-called bouting period. During these bouts, pyloric activity was slow and irregular (bottom lvn panel and PD trace are expanded recordings at time of vertical arrowhead). Regular pyloric activity recovered after this bouting phase (day 4). Arrowheads point to $-40 \mathrm{mV}$. Ivn recordings monitor the activity of three different pyloric cells types: LP neuron (largest action potentials), pyloric constrictor neurons (smallest action potentials), and PD neurons (intermediate action potentials).

in organ culture (Decentralized, Day 4). During the process of recovery, the pyloric rhythm undergoes a period of several hours in which it turns on and off irregularly for a few seconds to minutes at a time, a process termed "bouting" and illustrated in Figure 1 (Decentralized, Day 1).

\section{Decentralization modifies voltage-dependent ionic current levels}

In the lobster Jasus lalandii, the recovery of the pyloric rhythm is correlated with an increase in the ionic conductance level of $I_{\mathrm{h}}$ and a conductance decrease of the TEA-sensitive $\mathrm{K}^{+}$current component in PD neurons $4 \mathrm{~d}$ after decentralization (ThobyBrisson and Simmers, 2002). In Homarus gammarus, recovery was associated with an increase in $I_{\mathrm{A}} 4 \mathrm{~d}$ after decentralization (Mizrahi et al., 2001). This has been argued to be partly consistent with the acquisition of bursting properties not normally expressed by these cells (Thoby-Brisson and Simmers, 2002). In lobsters, however, the transitional bouting phase observed in crabs has not been reported. To establish whether similar conductance changes are observed in C. borealis, we measured several ionic currents during the entire recovery period.

Figure 2 (left column) shows examples of raw current traces of five voltage-gated currents we measured in C. borealis PD neurons: $I_{\mathrm{h}}, I_{\mathrm{A}}, I_{\mathrm{Ba}}, I_{\mathrm{KCa}}$, and $I_{\mathrm{Kd}}$. Figure 2 (middle column) shows examples of current-voltage plots of these currents before decentralization (open symbols/dashed lines) and $24 \mathrm{~h}$ after decentral-
Day 1

ization (solid symbols/lines). Changes in $I_{\mathrm{h}}, I_{\mathrm{Ba}}$, and $I_{\mathrm{KCa}}$ (measured at steady state) and in $I_{\mathrm{A}}$ were consistently observed, whereas $I_{\mathrm{Kd}}$ did not change. To determine the time course of these changes, we measured current densities of these voltagegated currents at 0,1 , and $4 \mathrm{~d}$ in organ culture in control preparations (no decentralization) and in preparations decentralized immediately after the day 0 measurements were taken. All data points were normalized to the measurements in the same cell at day 0 (Fig. 2, right column). Using a two-way mixed design ANOVA, we determined that there were statistically significant differences in the densities relative to nondecentralized control preparations of the following currents when all experimental groups were compared: $I_{\mathrm{h}}$ $(p<0.001 ; n=39), I_{\mathrm{Ba}}(p<0.05 ; n=$ 26), $I_{\text {KCa }}$ (steady state, $p<0.05 ; n=23$ ), and $I_{\mathrm{A}}(p<0.001 ; n=62)$ (Fig. 2, right column). Post hoc analysis indicates that these differences arise mainly from the changes observed at day 1 (Fig. 2). $I_{\mathrm{Kd}}$ (Fig. 2 , bottom) and the peak of $I_{\mathrm{KCa}}$ (data not shown) were not significantly affected over the period studied ( $p=0.80, n=22$; $p=0.28, n=23$, respectively). Compared with controls on day 1 , in decentralized preparations, the levels of $I_{\mathrm{h}}, I_{\mathrm{Ba}}$, and $I_{\mathrm{KCa}}$ (steady state) increased, and $I_{\mathrm{A}}$ decreased ( post hoc Tukey's tests; $I_{\mathrm{h}}, p<0.001 ; I_{\mathrm{Ba}}$, $\left.p=0.002 ; I_{\text {KCa }}, p=0.025 ; I_{\mathrm{A}}, p=0.03\right)$. Only the current density of $I_{\mathrm{h}}$ remained significantly elevated in decentralized preparations after $4 \mathrm{~d}(p=0.007)$, whereas the current densities of $I_{\mathrm{A}}, I_{\mathrm{Ba}}$, and $I_{\mathrm{KCa}}$ all returned to levels indistinguishable from control nondecentralized preparations (Fig. 2, right column). Current levels in nondecentralized preparations remained generally stable over time in organ culture except $I_{\mathrm{h}}$ and $I_{\mathrm{A}}$ that significantly decreased by day 4 compared with day 0 ( $p<0.01$ for both). Changes in decentralized preparations were significant with these trends taken into consideration.

Because $I_{\mathrm{Kd}}$ showed no tendency to change over time in either nondecentralized (control) or decentralized preparations and to avoid applications of $\mathrm{Ca}^{2+}$ current blockers (e.g., $\mathrm{Mn}^{2+}$ ) that could potentially interfere with normal physiological processes, we henceforth used $I_{\mathrm{HTK}}$ comprising $I_{\mathrm{Kd}}$ and $I_{\mathrm{KCa}}$ as a measure of $I_{\mathrm{KCa}}$. The same trends and their significance were observed when $I_{\text {HTK }}$ was used for our analyses (two-way mixed design ANOVA, $p<0.05 ; n=23$ ), although the relative level changes were smaller for $I_{\mathrm{HTK}}$ than $I_{\mathrm{KCa}}\left(\Delta I_{\mathrm{HTK}}\right.$ at day $1,131.1 \pm 30.2 \% ; \Delta I_{\mathrm{KCa}}$ at day 1 , $222.4 \pm 80.3 \%)$.

In a subset of experiments, measurements were made both immediately before and 10-30 min after decentralization. No significant current density differences were observed over this brief timespan (current densities measured 10-30 min after decentralization expressed as percentage of currents measured before decentralization in the same cell were as follows: $I_{\mathrm{HTK}}, 101 \pm$ $39 \% ; I_{\mathrm{A}}, 98 \pm 30 \% ; I_{\mathrm{h}}, 98 \pm 31 \%$; all $t$ test $p$ values were $>0.05$; 
$n=20)$. This indicates that long-term current changes are not the immediate effect of the neuromodulatory input removal.

No effects of decentralization or time in organ culture on neuronal input resistance were observed (Table 1). With the exception of $I_{\mathrm{Ba}}$, which sometimes showed a hyperpolarizing shift in its activation curve, we also did not observe significant changes in other conductance parameters (data not shown).

\section{Coregulation of ionic current pairs} depends on neuromodulatory input In our experiments, the current densities of all the currents studied in nondecentralized preparations on day 0 displayed a high level of variability $\left(I_{\mathrm{h}},-6.0 \pm 5.1 \mathrm{nA} / \mathrm{nF}\right.$; $I_{\mathrm{A}}, 97.5 \pm 21.0 \mathrm{nA} / \mathrm{nF} ; I_{\mathrm{HTK}}$ (steady state), $105.8 \pm 18.9 \mathrm{nA} / \mathrm{nF} ; I_{\mathrm{KCa}}, 66.2 \pm 34.7 \mathrm{nA} /$ $\mathrm{nF} ; I_{\mathrm{Kd}}, 53.9 \pm 26.4 \mathrm{nA} / \mathrm{nF} ; \mathrm{I}_{\mathrm{Ba}},-1.62 \pm$ $1.92 \mathrm{nA} / \mathrm{nF})$, similar to what has been reported for PD neurons previously (Goldman et al., 2000). Surprisingly, we found that the densities of $I_{\mathrm{h}}, I_{\mathrm{A}}$, and $I_{\mathrm{HTK}}$ or $I_{\mathrm{KCa}}$ significantly correlated with each other at all times during organ culture in nondecentralized preparations (Fig. 3A-C, Table 2). No other current density combination proved significantly correlated (data not shown). To confirm that correlation of $I_{\mathrm{A}}$ and $I_{\mathrm{h}}$ cannot simply be explained by correlation of each of these currents with $I_{\mathrm{HTK}}$, we performed multivariate analysis. If the effect of $I_{\mathrm{HTK}}$ was removed, the resulting partial correlation coefficient for the $I_{\mathrm{A}} / I_{\mathrm{h}}$ pair is still significant $(r=0.50$; $p<0.001$ ), which indicates that there is an independent relationship between $I_{\mathrm{A}}$ and $I_{\mathrm{h}}$. Using multivariate analysis, we further determined that the relationship among the three currents can be described as $I_{\mathrm{HTK}}$ $=120.85+0.97 \times I_{\mathrm{A}}+6.12 \times I_{\mathrm{h}}$.

The strong correlations between $I_{\mathrm{A}}$ versus $I_{\mathrm{HTK}}$ and $I_{\mathrm{h}}$ versus $I_{\mathrm{HTK}}$ observed in control preparations, however, disappeared $1 \mathrm{~d}$ after decentralization (Fig. 3D, Table 2), and the currents remained uncorrelated on day 4 after decentralization (Fig. 3E, Table 2). In contrast, $I_{\mathrm{h}}$ versus $I_{\mathrm{A}}$ remained strongly correlated at all times after decentralization (Fig. 3D,E, right column; Table 2), suggesting a mechanism of coregulation between $I_{\mathrm{h}}$ and $I_{\mathrm{A}}$ that is different from the mechanism that explains the coregulation of $I_{\mathrm{HTK}}$ and both $I_{\mathrm{A}}$ and $I_{\mathrm{h}}$.

We hypothesized that the lack of neuromodulator release, and/or the lack of rhythmic activity caused by decentralization, must mediate the changes in ionic current density and ionic current codependence shown in Figures 2 and 3. To test
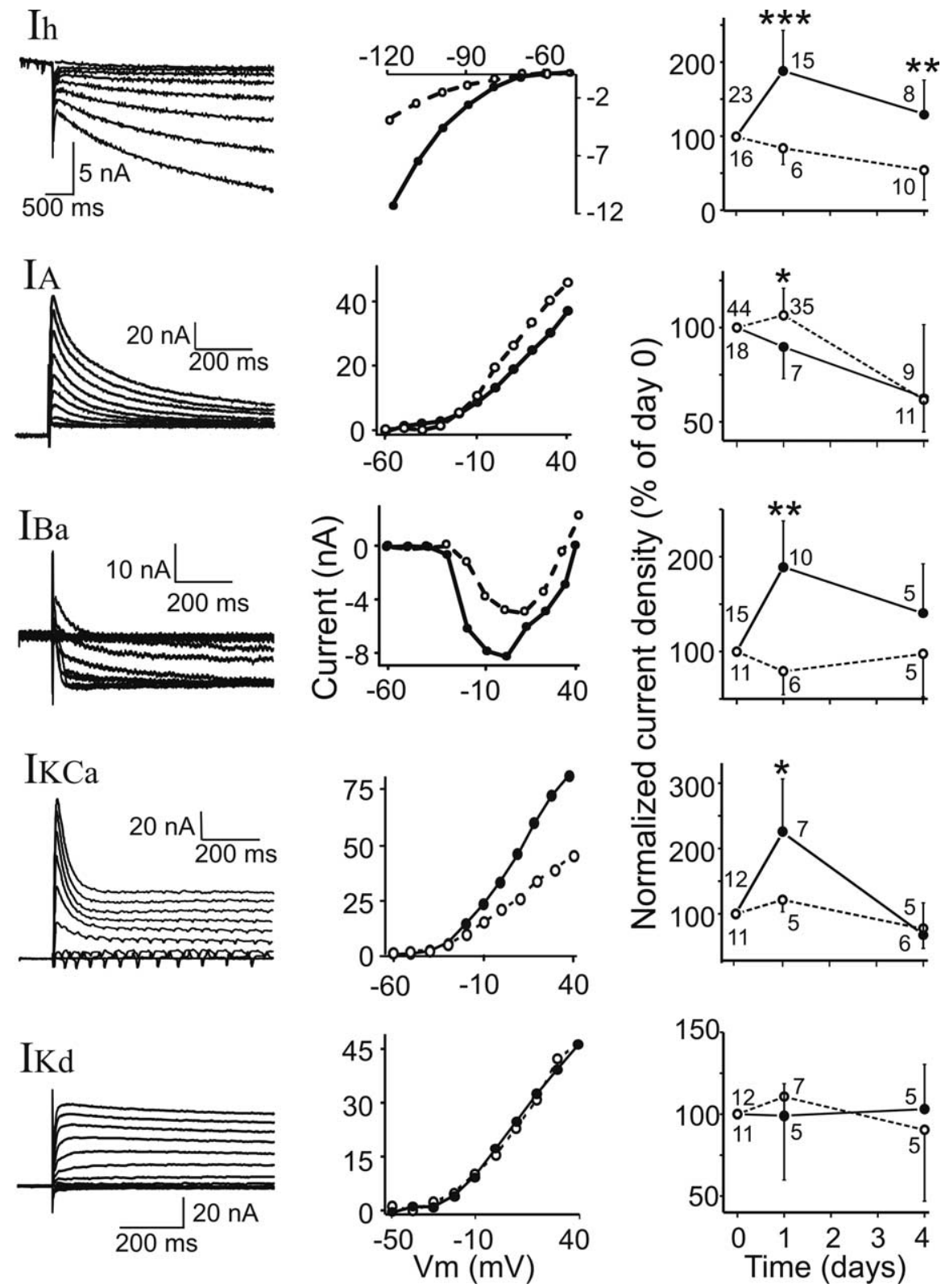

Figure 2. Decentralization affects ionic current densities in PD neurons. Left column, Examples of raw current traces. Currents are (from top to bottom) $I_{\mathrm{h}}, I_{\mathrm{A}}, I_{\mathrm{Ba}}, I_{\mathrm{KCa}}$ (steady state), and $I_{\mathrm{Kd}}$. Middle column, Examples of current-voltage plots of the five currents ( $I_{\mathrm{KCa}}$ measured at steady state). Open symbols/dashed lines are currents measured before decentralization. Solid symbols/lines are currents measured in the same cell $24 \mathrm{~h}$ after decentralization. Right column, Current densities measured in decentralized (solid symbols/lines) and nondecentralized (open symbols/dashed lines) preparations at days 0, 1, and 4 in organ culture. Current densities on days 1 and 4 are normalized to values measured in the same cell on day 0; no cell was impaled more than twice. A two-way mixed design ANOVA and post hoc Tukey's tests were used to compare data from decentralized and nondecentralized preparations day by day (comparisons for control preparations at different times are discussed in Results): ${ }^{*} p<$ $0.05,{ }^{* *} p<0.01,{ }^{* *} p<0.001$. Number of experiments is shown next to each point.

Table 1. Input resistance (in $\mathrm{M} \Omega$ ) changes during organ culture and decentralization

\begin{tabular}{llllll}
\hline & Day 0 & Day 1 & Day 2 & Day 4 & $p$ \\
\hline Control & $10.7 \pm 10.3$ & $9.4 \pm 6.1$ & $10.6 \pm 13.2$ & $11.9 \pm 10.2$ & \\
& $n=71$ & $n=35$ & $n=71$ & $n=71$ & 0.819 \\
Decentralized & $9.7 \pm 9.8$ & $10.6 \pm 16.8$ & $12.0 \pm 9.0$ & $8.8 \pm 7.6$ & \\
& $n=206$ & $n=174$ & $n=59$ & $n=43$ & 0.525 \\
\hline
\end{tabular}



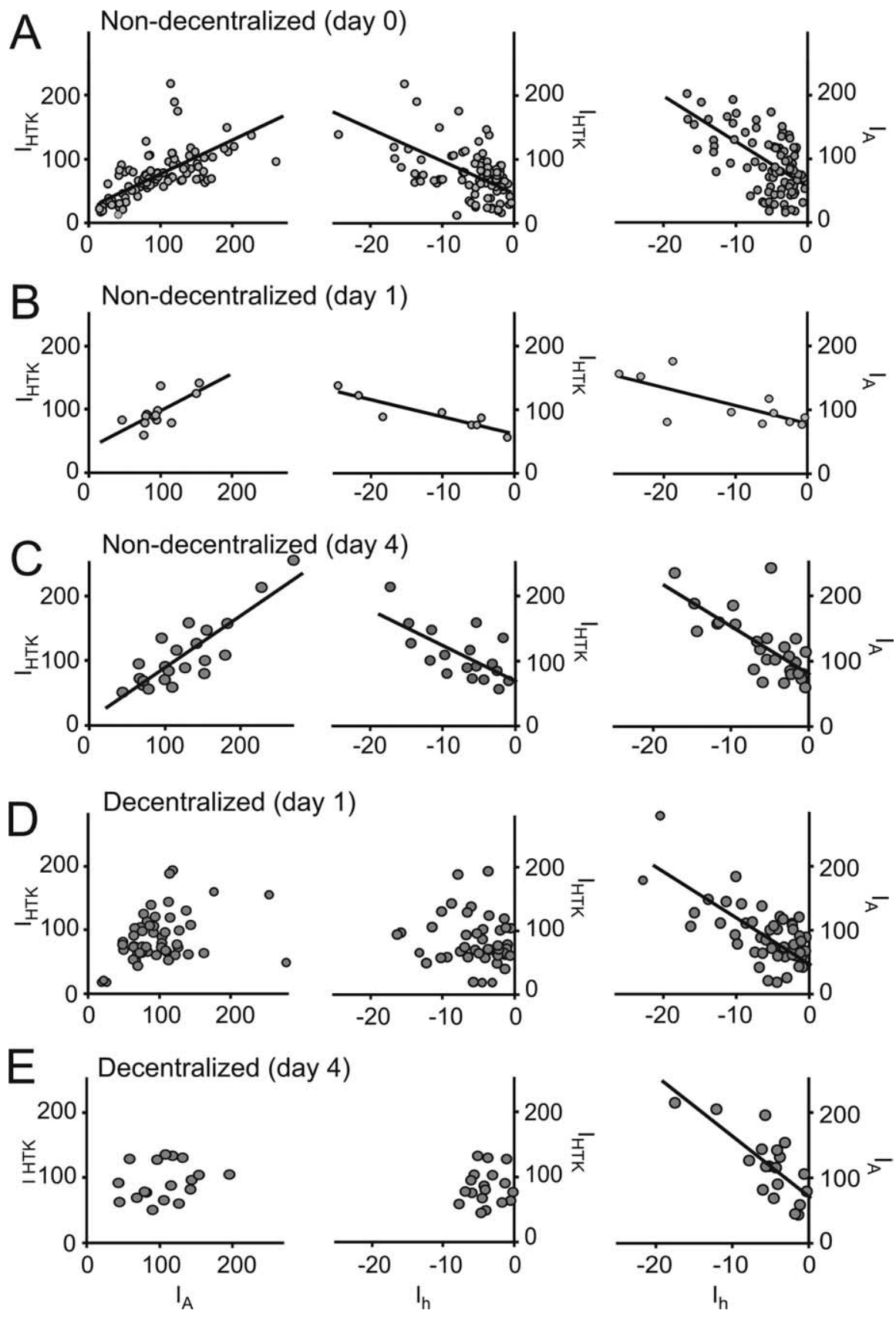

Figure 3. Coregulation of voltage-gated currents depends on continuous neuromodulatory input. Each point corresponds to current densities of the two indicated currents measured in an individual PD neuron. Not all current pairs were always measured in each cell, which resulted in different sample sets for the different current pairs. $A$, Currents measured on day 0 before decentralization. $\boldsymbol{B}$, Currents measured after $1 \mathrm{~d}$ in organ culture in nondecentralized preparations. $\boldsymbol{C}$, Currents measured after $4 \mathrm{~d}$ in organ culture in nondecentralized preparations. $\boldsymbol{D}$, Currents measured $1 \mathrm{~d}$ after decentralization. $\boldsymbol{E}$, Currents measured $4 \mathrm{~d}$ after decentralization. Lines are the result of linear regression analysis in each case and are plotted only for cases when correlation slopes were statistically significant $(p \leq 0.05)\left(R^{2}\right.$ and $p$ values are reported in Table 2$)$. All current densities are expressed in nanoamperes per nanofarads.

our hypothesis, we examined the effects of proctolin, one of the naturally released neuromodulators that can induce rhythmic activity when bath applied or when released onto the STG by projection neurons (Blitz and Nusbaum, 1999), on activity, on ionic current levels, and on current coregulations.

Proctolin prevents ionic current changes and loss of coregulation attributable to decentralization

Figure 4 illustrates the effects of proctolin on activity in control (nondecentralized) (Fig. 4A) and decentralized (Fig. 4B) prepa- rations. In nondecentralized preparation, after $15 \mathrm{~min}$ in proctolin (column 2), a slight increase in pyloric rhythm frequency and an increase in PD neuron oscillation amplitude are always observed. In preparations decentralized in normal saline, pyloric rhythm is always completely shut down $15 \mathrm{~min}$ after decentralization $(B$, column 1). However, if a preparation is decentralized in the presence of $10^{-6} \mathrm{M}$ proctolin, pyloric activity always remains strong and regular $(B$, column 2$)$. In these experiments, electrodes were removed after recording in proctolin on day 0 (column 2) and reinserted $24 \mathrm{~h}$ later still in the presence of bath-applied proctolin (column 3). Although regular pyloric activity continued uninterrupted during a $24 \mathrm{~h}$ application of proctolin in both control (Fig. $4 A$, column 3 ) and decentralized (Fig. $4 B$, column 3) preparations during reimpalement, we observed a slight decrease in the amplitude of the membrane potential oscillations (in 10 of 11 preparations). In the preparation shown, this change coincided with a slight decrease in the input resistance of PD neurons ( $R_{\text {in }}$ of $26.3 \mathrm{M} \Omega$ on day $0 ; R_{\text {in }}$ of $21.7 \mathrm{M} \Omega$ on day 1$)$. However, on average, input resistances of the preparations examined in this study were statistically indistinguishable at all stages (Table 1). We also sometimes observed a decrease in the amplitude of the inhibitory synaptic potentials that PD neurons receive from the single lateral pyloric (LP) neuron in the network (in 7 of 11 preparations) (Fig. $4 B$, column 3), which is consistent with observations previously reported in lobster (Thoby-Brisson and Simmers, 2002). Finally, during washout of proctolin, both control and decentralized preparations always slowed down and decreased the amplitude of the PD neuron membrane potential oscillations, consistent with well known effects of proctolin (Hooper and Marder, 1987; Nusbaum and Marder, 1989).

The acute application of proctolin did not significantly affect the current amplitudes of either $I_{\mathrm{HTK}}, I_{\mathrm{A}}$, or $I_{\mathrm{h}}$. After $15 \mathrm{~min}$ of $10^{-6} \mathrm{M}$ proctolin bath application in intact preparations current densities were as follows (in \% of densities in normal saline in the same cell): $I_{\mathrm{HTK}}, 114.9 \pm 46.7 \%$ $(p=0.273) ; I_{\mathrm{A}}, 95.1 \pm 25.0 \%(p=0.115) ; I_{\mathrm{h}}, 114.7 \pm 57.8 \%$ $(p=0.707) . p$ values are the result of paired $t$ tests $(n=15)$. The lack of acute effects of proctolin on these voltage-dependent currents has also been thoroughly documented previously (Golowasch and Marder, 1992b; Swensen and Marder, 2000). In these previous studies, proctolin was applied at various times after decentralization. Continuous application of $10^{-6} \mathrm{M}$ proctolin for $24 \mathrm{~h}$ in intact, nondecentralized, preparations produced no significant differences in current densities (in \% of densities in the 
Table 2. Linear regression analysis of ionic current density coordinated regulation

\begin{tabular}{|c|c|c|c|c|c|c|c|c|c|}
\hline & $I_{A}$ versu & & & $I_{\mathrm{h}}$ vers & & & $l_{\mathrm{h}}$ ver & & \\
\hline & $\overline{R^{2}}$ & $p$ & $n$ & $\overline{R^{2}}$ & $p$ & $n$ & $\overline{R^{2}}$ & $p$ & $n$ \\
\hline Control, day $0^{a}$ & 0.48 & $<0.0001$ & 95 & 0.37 & $<0.0001$ & 94 & 0.4 & $<0.0001$ & 89 \\
\hline Control, day 1 & 0.49 & 0.007 & 12 & 0.81 & 0.002 & 8 & 0.54 & 0.009 & 11 \\
\hline Control, day 4 & 0.73 & $<0.001$ & 22 & 0.44 & 0.002 & 21 & 0.50 & $<0.001$ & 28 \\
\hline Decentralized, day 1 & 0.06 & 0.07 & 52 & 0.02 & 0.22 & 48 & 0.55 & $<0.001$ & 51 \\
\hline Decentralized, day 4 & 0.05 & 0.35 & 19 & 0.01 & 0.76 & 19 & 0.56 & 0.0002 & 18 \\
\hline Control plus proctolin, day 1 & 0.88 & 0.01 & 5 & 0.92 & 0.02 & 5 & 0.89 & 0.05 & 5 \\
\hline Decentralized plus proctolin, day 1 & 0.87 & $<0.0001$ & 11 & 0.87 & $<0.0001$ & 11 & 0.83 & 0.0002 & 10 \\
\hline Decentralized plus proctolin plus TTX, day 1 & 0.73 & 0.002 & 9 & 0.65 & 0.05 & 6 & 0.87 & 0.0006 & 8 \\
\hline Control plus TTX, day 1 & 0.009 & 0.75 & 12 & 0.05 & 0.500 & 10 & 0.52 & 0.007 & 12 \\
\hline
\end{tabular}

Low $R^{2}$ values are shown in bold. Notice that these correspond only to decentralized and TTX-treated preparations (TTX effectively decentralizes the STG by blocking action potential transmission along the stn). Proctolin was bath applied at $1 \mu \mathrm{M}$ and TTX at $0.1 \mu \mathrm{M}$.

${ }^{a}$ Day 0 corresponds to pooled data of preparations measured on day 0 before decentralization for all experiments. Similar correlations and statistical significance were obtained for subsets of day 0 measurements corresponding to each experimental set listed below.

same cell on day 0$): I_{\mathrm{HTK}}, 110.8 \pm 28.8 \%$ $(p=0.431) ; I_{\mathrm{A}}, 91.9 \pm 46.1 \%(p=$ $0.816) ; I_{\mathrm{h}}, 110.1 \pm 44.2 \%(p=0.495) . p$ values are the result of paired $t$ tests $(n=$ 5). Similar results were obtained in the preparations decentralized and continuously maintained in the presence of proctolin for $24 \mathrm{~h}$ (in \% of densities in the same cell on day 0 before decentralization): $I_{\mathrm{HTK}}, 109.3 \pm 30.2 \%(p=0.36) ; I_{\mathrm{A}}, 94.0 \pm$ $27.6 \%(p=0.36) ; I_{\mathrm{h}}, 76.8 \pm 26.2 \%(p=$ 0.24 ) (Fig. 5).

Figure $6 A$ shows the effects of the continuous bath application of $1 \mu \mathrm{M}$ proctolin on ionic current coregulation. Ionic currents were measured, proctolin was applied, and the preparations were decentralized immediately thereafter. The preparations were then maintained in proctolin for $18-24 \mathrm{~h}$, and current densities were measured again. In the presence of proctolin, regular pyloric activity was maintained despite decentralization (Fig.

$4 B$, column 3$)$, and the three current pairs $\left(I_{\mathrm{A}} / I_{\mathrm{HTK}}, I_{\mathrm{h}} / I_{\mathrm{HTK}}\right.$, and $\left.I_{\mathrm{h}} / I_{\mathrm{A}}\right)$ remained correlated (Fig. $6 A$, Table 2 ), similar to nondecentralized preparations (Fig. $3 A-C$, Table 2 ) and in contrast to the effects of decentralization alone (Fig. $3 D, E$, Table 2). To determine whether the uninterrupted activity or uninterrupted neuromodulator supply accounted for the maintenance of current coregulation, rhythmic activity was suppressed with $0.1 \mu \mathrm{M}$ TTX applied together with $1 \mu \mathrm{M}$ proctolin $10 \mathrm{~min}$ before decentralization (Fig. 7, right) (Golowasch and Marder, 1992b). Bathapplied TTX not only blocks the generation of action potentials in STG motor neurons but also blocks the release of endogenous neuromodulators from axon terminals onto the STG, which eliminates subthreshold oscillatory activity. Blockade of action potentials only is not sufficient to block slow subthreshold oscillatory activity in STG neurons (Raper, 1979). We observed a similarly strong correlation of ionic currents in the presence of proctolin plus TTX (Fig. 6 B, Table 2), again similar to nondecentralized preparations (Table 2) or decentralized preparations treated with proctolin alone (Table 2 ). TTX application alone did not preserve the coregulation of $I_{\mathrm{A}} / I_{\mathrm{HTK}}$ and $I_{\mathrm{h}} / I_{\mathrm{HTK}}$, whereas $I_{\mathrm{h}} / I_{\mathrm{A}}$ coregulation was again not affected (Fig. $6 C$, Table 2 ), similar to the effects of decentralization alone (Fig. $3 D, E$, Table 2). The preservation of coregulation among these three currents in the presence of proctolin (or proctolin plus TTX) was accompanied by the elimination of the current density changes observed after decentralization (no proctolin application) relative to the levels of each current at day 0 (Fig. 5, white and black bars). Together with the complete loss of oscillatory activity in TTX plus proctolin, we take these results as evidence that proctolin, and not activity, regulates the coordinated expression of ionic currents in this system.

These results suggest the possibility that the "nondecentralized" ionic current density levels and their coregulation could be rescued by neuromodulators after the ionic currents have already undergone the decentralization-induced changes in current density and coregulation we observed. To address this possibility, we conducted two sets of experiments. In the first experiment, a reversible TTX/sucrose block of action potential transmission along the stn was used rather than stn transection (see Materials and Methods) to decentralize the preparations. After $\sim 24 \mathrm{~h}$, current densities were measured. At this point, the decentralized preparations have entered the so-called bouting stage of irregular pyloric activity, described by Luther et al. (2003) or, in some cases, fully recovered their pyloric rhythmic activity (Fig. 1, decentralized day 1 and 4). The stn block was then removed by extensive washing of the sucrose/TTX block with normal saline, and the preparation was maintained in organ culture for addi- 


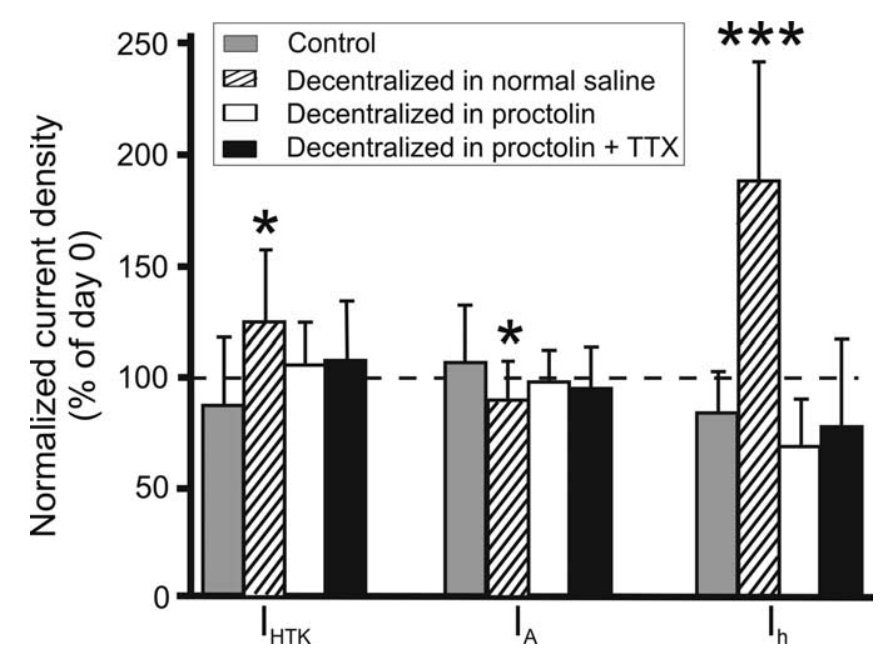

Figure 5. Neuromodulator prevents current density changes attributable to decentralization. Current densities on day 1 normalized to day 0 values are shown for $I_{\mathrm{HTK}}, I_{\mathrm{A}}$, and $I_{\mathrm{h}}$. Control, Nondecentralized preparations. Decentralized in normal saline, Preparations were decentralized on day 0 in normal saline. Decentralized in proctolin, Preparations were decentralized on day 0 in bath-applied $1 \mu \mathrm{m}$ proctolin. Decentralized in proctolin + TTX, Preparations were decentralized on day 0 in bath-applied $1 \mu \mathrm{m}$ proctolin plus $0.1 \mu \mathrm{m}$ TTX. Bars represent average $\pm S D$ of at least 12 experiments. ${ }^{*} p \leq 0.05,{ }^{* * *} p \leq 0.001$, statistically significant changes compared with day 0 (two-way mixed design ANOVA).
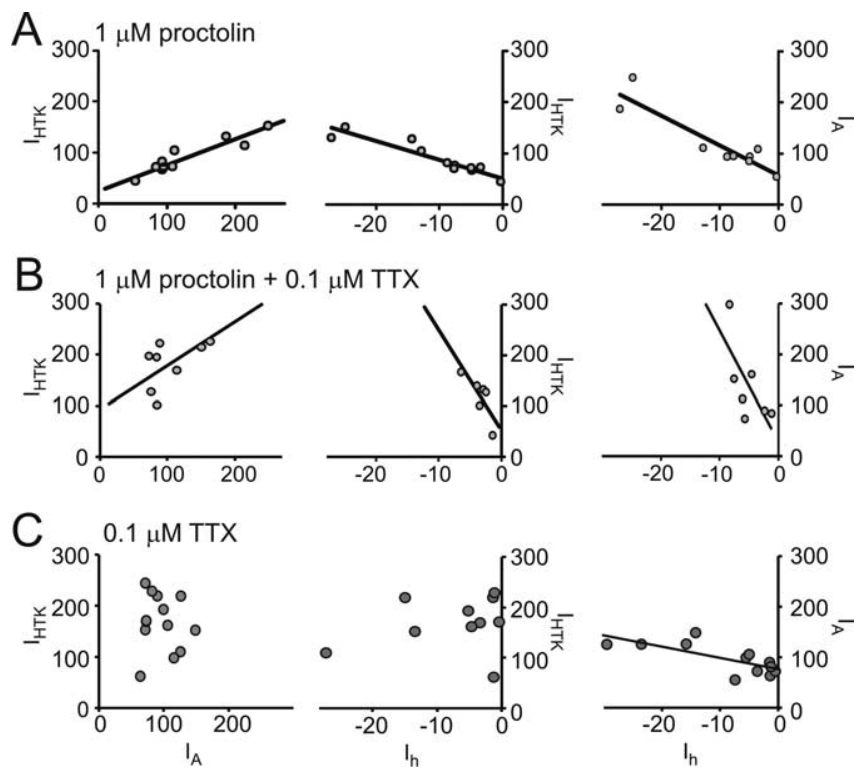

Figure 6. Exogenous neuromodulator bath application prevents the loss of current density coregulation in decentralized preparations. Each point corresponds to current density values of the two indicated currents measured in an individual PD neuron. Not all current pairs were always measured in each cell, which resulted in different sample sets for the different current pairs. $\boldsymbol{A}$, Decentralization in continuously bath-applied $1 \mu \mathrm{m}$ proctolin. $\boldsymbol{B}$, Decentralization in continuously bath-applied $1 \mu \mathrm{m}$ proctolin plus $0.1 \mu \mathrm{m}$ TTX. C, Nondecentralized preparations in continuously bath-applied $0.1 \mu \mathrm{m}$ TTX. Proctolin and TTX bath application were maintained for $18-24 \mathrm{~h}$, and measurements were made thereafter. Lines are the result of linear regression analysis in each case and are plotted only for cases when correlation slopes were statistically significant ( $p \leq 0.05)\left(R^{2}\right.$ and $p$ values are reported in Table 2). All currents are expressed in nanoamperes per nanofarads.

tional $24 \mathrm{~h}$, at which point current densities were measured one more time. We confirmed the effectiveness of the block, and of its removal, by stimulating the stn (on the side of the Vaseline well used for the block opposite to the STG) with 20-s-long trains of
$0.4 \mathrm{~ms}$ voltage pulses (1-2 V amplitude) at $10 \mathrm{~Hz}$. The stn block was deemed effective if stimulation for $20 \mathrm{~s}$ was unable to elicit change in pyloric activity; a block was deemed removed if similar stimulation could elicit the pyloric rhythm or change its frequency, at least for the duration of the stimulus. In the second set of experiments, preparations were decentralized by stn transection and kept in organ culture for $24 \mathrm{~h}$. At this point, current densities were measured. The preparations were then incubated in bath-applied $1 \mu \mathrm{M}$ proctolin for additional $24 \mathrm{~h}$. Currents were then measured for a second time. We expressed the day 2 changes relative to day 0 using population averages because we did not measure currents at day 0 in these preparations to avoid more than two impalements per cell (see Materials and Methods). The effect of these treatments on current density levels of $I_{\mathrm{HTK}}, I_{\mathrm{A}}$, and $I_{\mathrm{h}}$ are shown in Figure 8. The restoration of the full complement of endogenous neuromodulators by the removal of the stn block after $24 \mathrm{~h}$ (decentralization reversed after $24 \mathrm{~h}$ ) or the addition of exogenous proctolin ( $24 \mathrm{~h}$ decentralized then proctolin) were not able to restore the control levels of $I_{\mathrm{HTK}}$ or $I_{\mathrm{A}}$ densities observed before decentralization (day 0 ) or the levels of nondecentralized preparations at the same time point. In fact, the levels of $I_{\mathrm{HTK}}$ and $I_{\mathrm{A}}$ remained approximately equal to the levels observed in decentralized preparations on the same day in culture (but significantly higher than control in preparations in the case of $I_{\mathrm{HTK}}$ and significantly lower than control preparations in the case of $I_{\mathrm{A}} ; p<$ 0.05 for both). In contrast, the current density of $I_{\mathrm{h}}$ was closer to levels observed in control preparations. These results suggest that the effects of decentralization on ionic current levels are irreversible past a critical window of $\leq 24 \mathrm{~h}$.

The effect of the two treatments described above on the coregulation of currents is shown in Figure 9 (data combined). Not only was the coregulation of the pairs $I_{\mathrm{A}} / I_{\mathrm{HTK}}$ and $I_{\mathrm{h}} / I_{\mathrm{HTK}}$ not recovered by continuous proctolin bath application starting $24 \mathrm{~h}$ after decentralization or by reestablishing normal action potential transmission along the stn, but the robust coregulation we observed of the $I_{\mathrm{h}} / I_{\mathrm{A}}$ pair was further lost (compare Fig. 3, right columns, with Fig. 9). These results suggest that prolonged removal of neuromodulators causes a restructuring of the signaling pathway connecting the neuromodulator receptors and their ion channel effectors.

\section{Discussion}

Our results reveal a hitherto unknown role of neuromodulators, namely that of controlling the codependence of ionic currents (in this particular system of $I_{\mathrm{HTK}}, I_{\mathrm{A}}$, and $I_{\mathrm{h}}$ ). We show that this effect is likely to be mediated by neuromodulators (such as proctolin) directly rather than indirectly via electrical activity changes. Proctolin is known to activate a peptide-specific current (Golowasch and Marder, 1992b; Swensen and Marder, 2000) via a metabotropic receptor (Swensen and Marder, 2000). Acute effects of proctolin on other ionic currents have not been reported previously. Our results suggest that proctolin has effects on several other voltage-gated currents expressed by PD neurons that are not acutely apparent and are revealed when neuromodulatory input (including proctolin) to the STG is removed. At this point, it is unknown whether the acute effects of proctolin on the peptide-activated current and the long-term effects on the amplitude and coregulation of other voltage-gated currents are mediated by the same or by distinct signaling pathways linked to the proctolin receptor.

An activity-independent mechanism linking $I_{\mathrm{A}}$ and $I_{\mathrm{h}}$ has been shown in PD neurons in lobster (MacLean et al., 2003), apparently acting at the transcription level (Schulz et al., 2006). 
Our results are consistent with this mechanism because the $I_{\mathrm{A}} / I_{\mathrm{h}}$ coregulation does not appear to be significantly affected by the loss of rhythmic activity. However, we show that $I_{\mathrm{A}}$ and $I_{\mathrm{h}}$ both covary with $I_{\mathrm{HTK}}$, in a manner that appears to be independent of the covariation between $I_{\mathrm{A}}$ and $I_{\mathrm{h}}$ and of activity but controlled by the neuromodulatory input to the pyloric network. Furthermore, the loss of current coregulation after decentralization can be prevented by exogenous neuromodulators only during a critical window lasting for an as yet undetermined period no longer than $24 \mathrm{~h}$ after decentralization. This period coincides with the critical window after decentralization during which RNA synthesis is required for rhythmic pyloric activity recovery in lobster (ThobyBrisson and Simmers, 2000). Thus, a possible mechanism underlying the coregulation of currents by neuromodulator could be the simultaneous regulation of the expression of multiple genes (cf. Adams and Dudek, 2005) in conjunction with a relatively fast turnover rate of the channels involved. Alternatively, ion channels can also express enzymatic activity, which could regulate inter-ion channel activation directly (Runnels et al., 2001; Cai et al., 2005). The existence of multi-molecular complexes, including ion channels, enzymes, and cofactors capable of recruiting and activating enzymes (Catterall et al., 2006; Levitan, 2006), may provide the molecular framework for the coordinated regulation of multiple channels.

Our data show that most ionic currents affected in PD neurons by decentralization show transient current density changes that are maximal at a time during the recovery (day 1) when pyloric rhythm displays a high degree of instability characterized by intermittent bouts of pyloric activity (Luther et al., 2003). Preliminary evidence indicates that this is also true for other neuronal types in the network. These transient changes may in fact be responsible for bouting behavior, as suggested by similar current changes during bouting observed in a conductance-based model of PD neuron decentralization (Zhang and Golowasch, 2007).

Sustained rhythmic activity in nondecentralized preparations is in large part driven by an additional inward current activated by neuromodulators (Golowasch et al., 1992; Swensen and Marder, 2000). This neuromodulator-gated current is activated by proctolin and is thought to be inactive in decentralized preparations attributable to the abolished release of neuromodulators, yet rhythmic activity slowly recovers back to near control levels (Thoby-Brisson and Simmers, 1998; Luther et al., 2003). It is in principle possible that the neuromodulator-gated current activated by proctolin after decentralization becomes constitutively active and independent of the peptide, thus reactivating the pyloric rhythm. Alternatively, two effects may compensate for the prolonged removal of neuromodulator-gated currents and help restore rhythmic network activity. (1) A subset of the voltagegated ionic currents irreversibly change in amplitude relative to control levels during the recovery after decentralization (i.e., $I_{\mathrm{h}}$ ); this may be sufficient to restore the ionic current balance and rhythmic activity of the neuron. (2) The change in coregulation of a subset of voltage-gated currents (i.e., $I_{\mathrm{h}}, I_{\mathrm{A}}$, and $I_{\mathrm{HTK}}$ ) after decentralization may be sufficient to alter the balance of conductances to a state that restores rhythmic activity in key neurons, such as the PD neurons that are strongly coupled to the pacemaker $\mathrm{AB}$ neuron. As a consequence, the entire network may recover its rhythmic pattern of activity. Our preliminary data

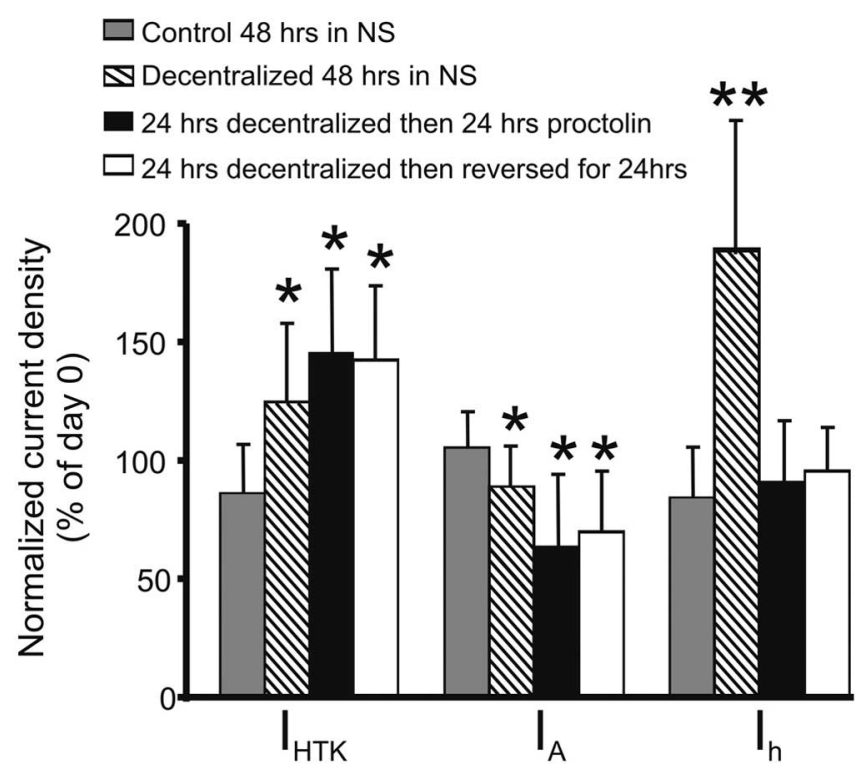

Figure 8. Neuromodulator applied past a critical window after decentralization does not restore control current densities. Control $48 \mathrm{~h}$ in NS, Nondecentralized preparations were kept in organ culture for $48 \mathrm{~h}$ in normal saline $(n=5)$. Decentralized $48 \mathrm{~h}$ in NS, Preparations were decentralized and then kept in organ culture for $48 \mathrm{~h}$ in normal saline $(n=20) .24 \mathrm{~h}$ decentralized then $24 \mathrm{~h}$ proctolin, Preparations were decentralized and the preparation was placed in organ culture for $\sim 24 \mathrm{~h}$. Current densities were then measured (day 1 ) and placed in bathapplied $1 \mu$ m proctolin $(n=12) .24 \mathrm{~h}$ decentralized then reversed for $24 \mathrm{~h}$, Sucrose/TTX block of the input nerve stn was removed after $24 \mathrm{~h}$ and the currents were measured. Eighteen to $24 \mathrm{~h}$ later, currents were measured again $(n=14)$. Bars represent current densities ( \pm SD) normalized to day 0 using population averages. Currents were compared with levels on day 0 using a mixed design two-way ANOVA $\left({ }^{*} p \leq 0.05,{ }^{* *} p \leq 0.01\right)$.

indicate that different neurons in the network respond differently to long-term decentralization. Additionally, synaptic changes may also occur as suggested by Thoby-Brisson and Simmers (2002).

Thus, the pyloric network recovery of activity is likely the result of a complex interplay and balance of ionic current and synaptic changes across the entire network. It is possible that the high degree of consistency of pyloric network activity across individuals (Bucher et al., 2005) is the result of conductance coregulation set by neuromodulatory input. Conversely, our data indicate that coordinated expression of ionic currents is not by itself necessary to ensure a stable neuronal output because stable output was restored even in the absence of their coordinated expression. Perhaps it is precisely the loss of coregulation that, in combination with other synaptic and/or ionic current changes, releases certain constraints imposed on the network under normal conditions to allow the recovery of rhythmic activity to 

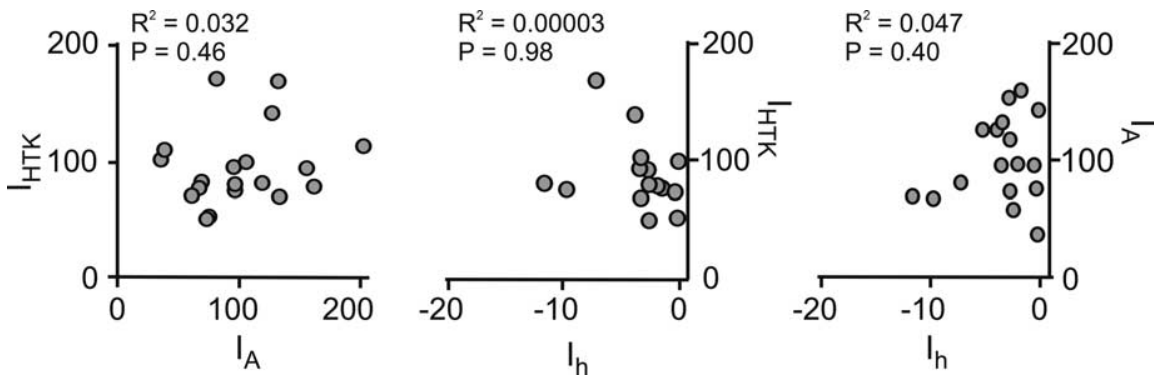

Figure 9. Effect of neuromodulators on the coregulation of ionic currents after long-term decentralization. Each point corresponds to current density values of the two indicated currents measured in an individual PD neuron. Not all current pairs were always measured in each cell, which resulted in different sample sets for the different current pairs. Experiments were conducted as described in Figure 8. ANCOVA analysis of the data from the two sets of experiments showed no difference in the linear regressions, and data were pooled together. Shown on each panel are coefficients of determination $\left(R^{2}\right)$ and statistical significance $(p)$ of the regression slopes. All currents are expressed in nanoamperes per nanofarads.

within functional levels. Although a large degree of ionic current variability can theoretically sustain specific types of neuronal activity (Goldman et al., 2001; Prinz et al., 2004), a restriction of the global current variability by coregulation can help to ensure the maintenance of activity within functional limits (Goldman et al., 2001; MacLean et al., 2003, 2005; Burdakov, 2005) in the intact system. However, the release from the coregulated condition plus significant current density changes of a subset of ionic currents may be required to ensure the recovery of specific activity patterns, such as the pyloric activity pattern, when one of the ionic currents responsible for rhythm generation is lost [i.e., the neuromodulator-gated current (Swensen and Marder, 2000)]. Ionic current coregulation may also play other, as yet unidentified, roles, e.g., gain adjustment (Burdakov, 2005). Finally, conductance parameters other than those identified by us, which could contribute to the restoration of the functional output of the network, may also be subject to coregulation (McAnelly and Zakon, 2000). These results highlight the complexity of the balance of conductances and their properties in the generation of neuronal activity and that potentially many important factors regulating neuronal activity remain to be identified.

\section{References}

Adams JP, Dudek SM (2005) Late-phase long-term potentiation: getting to the nucleus. Nat Rev Neurosci 6:737-743.

Blitz DM, Nusbaum MP (1999) Distinct functions for cotransmitters mediating motor pattern selection. J Neurosci 19:6774-6783.

Bucher D, Prinz AA, Marder E (2005) Animal-to-animal variability in motor pattern production in adults and during growth. J Neurosci 25:1611-1619.

Burdakov D (2005) Gain control by concerted changes in I(A) and I(H) conductances. Neural Comput 17:991-995.

Cai SQ, Hernandez L, Wang Y, Park KH, Sesti F (2005) MPS-1 is a $\mathrm{K}^{+}$ channel beta-subunit and a serine/threonine kinase. Nat Neurosci 8:1503-1509.

Catterall WA, Hulme JT, Jiang X, Few WP (2006) Regulation of sodium and calcium channels by signaling complexes. J Recept Signal Transduct Res 26:577-598.

Davis GW (2006) Homeostatic control of neural activity: from phenomenology to molecular design. Annu Rev Neurosci 29:307-323.

Desai NS, Rutherford LC, Turrigiano GG (1999) Plasticity in the intrinsic excitability of cortical pyramidal neurons. Nat Neurosci 2:515-520.

Galante M, Avossa D, Rosato-Siri M, Ballerini L (2001) Homeostatic plasticity induced by chronic block of AMPA/kainate receptors modulates the generation of rhythmic bursting in rat spinal cord organotypic cultures. Eur J Neurosci 14:903-917.

Gibson JR, Bartley AF, Huber KM (2006) Role for the subthreshold currents ILeak and IH in the homeostatic control of excitability in neocortical somatostatin-positive inhibitory neurons. J Neurophysiol 96:420-432.

Goldman MS, Golowasch J, Marder E, Abbott LF (2000) Dependence of firing pattern on intrinsic ionic conductances: sensitive and insensitive combinations. Neurocomputing 32-33:141-146.

Goldman MS, Golowasch J, Marder E, Abbott LF (2001) Global structure, robustness, and modulation of neuronal models. J Neurosci 21:5229-5238.

Golowasch J, Marder E (1992a) Ionic currents of the lateral pyloric neuron of the stomatogastric ganglion of the crab. J Neurophysiol 67:318-331

Golowasch J, Marder E (1992b) Proctolin activates an inward current whose voltage dependence is modified by extracellular $\mathrm{Ca}^{2+}$. J Neurosci 12:810-817.

Golowasch J, Buchholtz F, Epstein IR, Marder E (1992) Contribution of individual ionic currents to activity of a model stomatogastric ganglion neuron. J Neurophysiol 67:341-349.

Golowasch J, Abbott LF, Marder E (1999a) Activity-dependent regulation of potassium currents in an identified neuron of the stomatogastric ganglion of the crab Cancer borealis. J Neurosci 19:RC33(1-5).

Golowasch J, Casey M, Abbott LF, Marder E (1999b) Network stability from activity-dependent regulation of neuronal conductances. Neural Comput 11:1079-1096.

Golowasch J, Goldman MS, Abbott LF, Marder E (2002) Failure of averaging in the construction of a conductance-based neuron model. J Neurophysiol 87:1129-1131.

Gonzalez-Islas C, Wenner P (2006) Spontaneous network activity in the embryonic spinal cord regulates AMPAergic and GABAergic synaptic strength. Neuron 49:563-575.

Haedo RJ, Golowasch J (2006) Ionic mechanism underlying recovery of rhythmic activity in adult isolated neurons. J Neurophysiol 96:1860-1876.

Harris-Warrick RM (1992) Dynamic biological networks: the stomatogastric nervous system. Cambridge, MA: MIT.

Hong SJ, Lnenicka GA (1995) Activity-dependent reduction in voltagedependent calcium current in a crayfish motoneuron. J Neurosci 15:3539-3547.

Hooper SL, Marder E (1987) Modulation of the lobster pyloric rhythm by the peptide proctolin. J Neurosci 7:2097-2112.

Levitan IB (2006) Signaling protein complexes associated with neuronal ion channels. Nat Neurosci 9:305-310.

Linsdell P, Moody WJ (1994) $\mathrm{Na}^{+}$channel mis-expression accelerates $\mathrm{K}^{+}$ channel development in embryonic Xenopus laevis skeletal muscle. J Physiol 480:405-410.

Liu Z, Golowasch J, Marder E, Abbott LF (1998) A model neuron with activity-dependent conductances regulated by multiple calcium sensors. J Neurosci 18:2309-2320.

Luther JA, Robie AA, Yarotsky J, Reina C, Marder E, Golowasch J (2003) Episodic bouts of activity accompany recovery of rhythmic output by a neuromodulator- and activity-deprived adult neural network. J Neurophysiol 90:2720-2730.

MacLean JN, Zhang Y, Johnson BR, Harris-Warrick RM (2003) Activityindependent homeostasis in rhythmically active neurons. Neuron 37:109-120.

MacLean JN, Zhang Y, Goeritz ML, Casey R, Oliva R, Guckenheimer J, Harris-Warrick RM (2005) Activity-independent coregulation of IA and Ih in rhythmically active neurons. J Neurophysiol 94:3601-3617.

McAnelly ML, Zakon HH (2000) Coregulation of voltage-dependent kinetics of $\mathrm{Na}^{+}$and $\mathrm{K}^{+}$currents in electric organ. J Neurosci 20:3408-3414.

Mizrahi A, Dickinson PS, Kloppenburg P, Fenelon V, Baro DJ, HarrisWarrick RM, Meyrand P, Simmers J (2001) Long-term maintenance of channel distribution in a central pattern generator neuron by neuromodulatory inputs revealed by decentralization in organ culture. J Neurosci 21:7331-7339.

Nusbaum MP, Marder E (1989) A modulatory proctolin-containing neu- 
ron (MPN). II. State-dependent modulation of rhythmic motor activity. J Neurosci 9:1600-1607.

Prinz AA, Bucher D, Marder E (2004) Similar network activity from disparate circuit parameters. Nat Neurosci 7:1345-1352.

Rabbah P, Golowasch J, Nadim F (2005) Effect of electrical coupling on ionic current and synaptic potential measurements. J Neurophysiol 94:519-530.

Raper JA (1979) Nonimpulse-mediated synaptic transmission during the generation of a cyclic motor program. Science 205:304-306.

Runnels LW, Yue L, Clapham DE (2001) TRP-PLIK, a bifunctional protein with kinase and ion channel activities. Science 291:1043-1047.

Saghatelyan A, Roux P, Migliore M, Rochefort C, Desmaisons D, Charneau P, Shepherd GM, Lledo PM (2005) Activity-dependent adjustments of the inhibitory network in the olfactory bulb following early postnatal deprivation. Neuron 46:103-116.

Schulz DJ, Goaillard JM, Marder E (2006) Variable channel expression in identified single and electrically coupled neurons in different animals. Nat Neurosci 9:356-362.

Selverston AI, Russell DF, Miller JP (1976) The stomatogastric nervous system: structure and function of a small neural network. Prog Neurobiol 7:215-290.

Spitzer NC (2006) Electrical activity in early neuronal development. Nature 444:707-712.

Swensen AM, Marder E (2000) Multiple peptides converge to activate the same voltage-dependent current in a central pattern-generating circuit. J Neurosci 20:6752-6759.

Thoby-Brisson M, Simmers J (1998) Neuromodulatory inputs maintain expression of a lobster motor pattern-generating network in a modulationdependent state: evidence from long- term decentralization in vitro. J Neurosci 18:2212-2225.

Thoby-Brisson M, Simmers J (2000) Transition to endogenous bursting after long-term decentralization requires de novo transcription in a critical time window. J Neurophysiol 84:596-599.

Thoby-Brisson M, Simmers J (2002) Long-term neuromodulatory regulation of a motor pattern-generating network: maintenance of synaptic efficacy and oscillatory properties. J Neurophysiol 88:2942-2953.

Turrigiano GG (1999) Homeostatic plasticity in neuronal networks: the more things change, the more they stay the same. Trends Neurosci 22:221-227.

Turrigiano GG, Nelson SB (2004) Homeostatic plasticity in the developing nervous system. Nat Rev Neurosci 5:97-107.

Turrigiano G, Abbott LF, Marder E (1994) Activity-dependent changes in the intrinsic properties of cultured neurons. Science 264:974-977.

Xu J, Kang N, Jiang L, Nedergaard M, Kang J (2005) Activity-dependent long-term potentiation of intrinsic excitability in hippocampal CA1 pyramidal neurons. J Neurosci 25:1750-1760.

Zhang Y, Golowasch J (2007) Modeling recovery of rhythmic activity: hypothesis for the role of a calcium pump. Neurocomputing 70:1657-1662. 